\section{Continuing confusion}

SIR - Beck ${ }^{1}$ claims that the sex ratio (proportion of males at birth) of artists' offspring is high. Mueller ${ }^{2}$ offers the Trivers-Willard hypothesis ${ }^{3}$, an 'appropriate theoretical framework' to account for such a finding.

But even if Beck is right, I suggest that Mueller's judgement is premature. Mammalian ${ }^{4}$ (and among them, human ${ }^{5}$ ) sex ratios depend on many variables. Some of this variation is consistent with the Trivers-Willard hypothesis and some is not. For instance, some human diseases (such as prostatic cancer ${ }^{6}$ and hepatitis $B^{7}$ ) are associated with the production of male, not female, offspring. But it is not yet possible to tell whether any given sex ratio bias is adaptive or the consequence of some physiological constraint.

I have suggested that the problem should best be tackled by examining the proximate mechanisms underlying sex ratio variations ${ }^{8}$ which are likely to be far fewer than the number of variables with which sex ratio has been found to vary. So it would seem sensible to ask whether these mechanisms (rather than the variables) behave in conformity with adaptive hypotheses. I have proposed that the sex ratio of mammalian offspring is partially controlled by parental gonadotrophin and steroid hormone levels at the time of conception?. In men, illness of various sorts is associated with high gonadotrophin and low testosterone levels ${ }^{10}$ and, ex hypothesi, with low offspring sex ratios (thus presumably conforming with the Trivers-Willard hypothesis). I have also given grounds for suggesting that people suffering from, or destined to suffer from, prostatic cancer or hepatitis B have high testosterone levels ${ }^{11}$. If this is correct, the high sex ratios of the offspring of these people may come to be viewed as a result of a physiological constraint rather than evidence against Trivers and Willard. But such matters should be settled before elevating their hypothesis into a 'theoretical framework'

William H. James

Galton Laboratory,

Department of Genetics and Biometry,

University College London,

Wolfson House,

4 Stephenson Way, London NW1 2HE, UK

SiR - I respond to Ulrich Mueller's comment on social status and sex (ratio of offspring), based on an examination of biographical compilations ${ }^{2}$. The authors are presumably interested in the biological phenomenon of sex ratio at (live) birth. The representation of children in compilations such as Who's Who is a socially stressed report that is subject to a variety of distortions: reporting of perinatal mortality, illegitimacy, children of plural mar- riages, adoption and repudiation: all these are likely to be biased by social class and by sex. The data given can hardly be accepted at face value. If they were to be, we would then have to remove confounding with variables such as parity and age of mother, as well as differential prenatal mortality that may be associated with infection, malnutrition and other socially correlated causes.

Unfortunately, it is difficult to find large datasets organized by biological family relationship. The large population census datasets are acquired by household rather than family, and are beset with many errors in statistical detail ${ }^{12}$.

\section{Joshua Lederberg}

The Rockefeller University, 1230 York Avenue,

New York, New York 10021-6399, USA

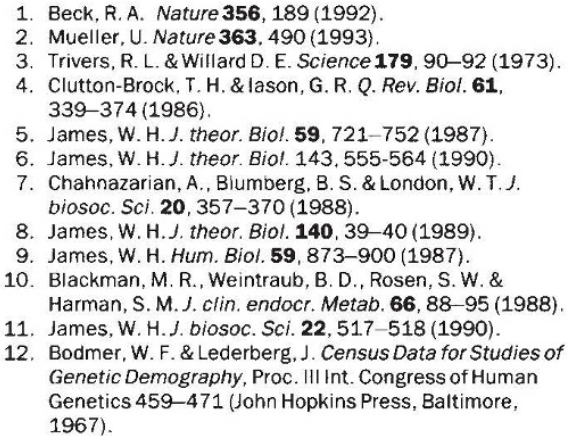
Genetic Demography, Proc. III Int. Congress of Human Genetics 459-471 (John Hopkins Press, Baltimore, 1967)

\section{Gaining time}

SIR - The leading article in News and Views on "Competition and the death of science" (Nature 363, 667;1993) raises important points about the dangers of competition. It also illustrates another important point about the funding of science in general. The allocation of large sums of money to some fields is a good illustration of the law of diminishing returns and is probably not an efficient use of resources (including human capital).

There are fields in which advances are strongly limited by funding. As a result, it is often not the best scientists (nor the best ideas) that get funded but those willing to switch to less basic but more easily funded projects. We are forced to consider not whether an experiment tests an important hypothesis but whether it will attract funding. An increase in funding could have a major impact in such fields, where advances may now have to wait 5 or 10 years because of funding problems. It is not that we do not have clear testable hypotheses or the knowledge and techniques to test them. Needless to say, this results in considerable frustration and depression among the workers in such fields. Both society and the individuals lose.
In contrast, there are fields where if one person is not funded, the experiment will probably be completed in another laboratory within a few months. Large sums of money are thus seemingly being spent to advance science by a short time. Perhaps more balanced funding would bring about a more efficient use of resources.

Research councils should therefore consider developing a system which will include the following simple question. "If we fund a project in field $\mathrm{A}$ (assuming the referees agree that it has a clear, logical and testable goal) does it have the potential to advance the field by a few months or by a few years or a decade?" I suggest that money be invested where the largest gains in time are probable.

Jerry W. Leverenz

Department of Plant Physiology,

University of Umeå,

S-90187 Umeå, Sweden

\section{Polluter pays}

SIR - Your suggestion in the leading article "Environmental protection or imperialism?" (Nature 363, 657;1993) that underdeveloped countries may not be able to afford environmental protection might have some merit with respect to goods produced for home consumption, but there is no reason why affluent customers should not pay the full price of production, including the price of the safe disposal of the pollutants produced in the process of manufacture. Neither is there any reason why pollution control should be more expensive in undeveloped than in developed countires, nor why multinational corporations that depend on worldwide markets should not (through prices charged to their customers) protect the environment wherever they are.

Your gratuitous accusation that we in the United States are motivated more by fear of the loss of jobs than by concern for the environment is similar to my accusing you of caring more for the profits of multinational corporations than for the environment - but I wouldn't say a thing like that.

\section{Nevin Weaver}

Box 177,

Barnstable,

Massachusetts, 02630, USA

\section{Now we know}

SIR - Although a British MP once pronounced that dogs do not have DNA, can there be a single member of the public that does not know that dinosaurs had DNA? Janice Taverne

University College London Medical School, Arthur Stanley House,

40-50 Tottenham Street,

London W1P 9PG, UK 